\title{
Evaluasi Kepuasan Pelayanan Pengguna Aplikasi OPAC Perpustakaan STMIK AMIKOM Yogyakarta
}

\author{
Fatimah Nur Arifah*1, Abidarin Rosidi' ${ }^{2}$, Hanif Al Fatta ${ }^{3}$ \\ ${ }^{1,2,3}$ Magister Teknik Informatika, STMIK AMIKOM Yogyakarta \\ E-mail: ${ }^{* 1}$ mizzchriz@gmail.com, ${ }^{2}$ abi@ amikom.ac.id, ${ }^{3}$ hanif.a@amikom.ac.id
}

\begin{abstract}
Abstrak
Penelitian ini bertujuan untuk mengetahui dan mengukur tingkat kepuasan pengguna terhadap aplikasi Online Public Access Catalog (OPAC) pada Perpustakaan STMIK AMIKOM Yogyakarta. Subjek penelitian ini ialah mahasiswa yang terdaftar sebagai anggota perpustakaan dan objek penelitian ini adalah aplikasi OPAC Perpustakaan STMIK AMIKOM Yogyakarta. Analisis data dalam penelitian ini menggunakan diagram Importance Performance Analysis (IPA) dipadukan dengan Indeks Kepuasan Pengguna (IKP) didasarkan pada indikator-indikator dari lima dimensi End User Computing Satisfaction yaitu isi (content), keakuratan (accuracy), bentuk (format), kemudahan penggunaan (ease of use) dan ketepatan waktu (timeliness). Hasil penelitian menunjukkan pengguna OPAC Perpustakaan STMIK AMIKOM Yogyakarta cukup puas dengan hasil perhitungan IKP 78,01 \%. Penelitian ini diharapkan dapat memberi masukan pada pengelola OPAC sebagai bahan acuan untuk meningkatkan kinerja OPAC.
\end{abstract}

Kata Kunci - End User Computing Satisfaction, OPAC, Perpustakaan,IPA

\begin{abstract}
This study aims to identify and measure the level of satisfaction of users of the application Online Public Access Catalog (OPAC) in the library STMIK AMIKOM Yogyakarta. These subjects are students who are registered as members of the library and the object of this study is OPAC STMIK Library AMIKOM Yogyakarta. Analysis of the data in this study using a diagram of Importance Performance Analysis (IPA) which is combined with User Satisfaction Index (IKP) based on the five dimensions of End User Computing Satisfaction; content, accuracy, format, ease of use and timeliness. The results showed users of OPAC STMIK AMIKOM Yogyakarta quite satisfied with the results of the calculation IKP 78.01\%. This research is expected to provide input to the manager of the OPAC as a reference to improve performance of the OPAC.
\end{abstract}

Keyword $\mathbf{s}$ - End User Computing Satisfaction, OPAC, Library,IPA

\section{PENDAHULUAN}

Berdasarkan hasil wawancara dengan Kepala Resource Center (2013), Perpustakaan STMIK AMIKOM Yogyakarta saat ini sudah menggunakan sistem informasi baik untukmendukung kinerja intern perpustakaan maupun untuk layanan kepada para penggunaumum Perpustakaan STMIK AMIKOM Yogyakarta dilengkapi OPAC (Online Public Access Catalog). Harapan pihakperpustakaan akanpemanfaatan OPACtersebut adalahdapat meningkatkan citra perpustakaan yang berdampak positif pada kepuasan pemustaka. Oleh karena itu, perlu dilakukan evaluasi kepuasan pengguna OPAC Perpustakaan STMIK AMIKOM Yogyakarta.

Adapun tujuan penelitian adalah untuk mengevaluasi kepuasan pengguna OPAC Perpustakaan STMIK AMIKOM Yogyakarta. Sedangkan batasan dan metode penelitian yang digunakan ialah: 
1. Beberapa stakeholder yang terlibat dalam penelitian ini adalah mahasiswa aktif yang menggunakan aplikasi OPAC melalui LAN di Perpustakaan STMIK Amikom Yogyakarta dan melalui WAN atau internet di luar Perpustakaan STMIK Amikom Yogyakarta.

2. Analisis data menggunakan rumus Mean, Importance Performance Analysis (IPA)serta Indeks Kepuasan Pengguna (IKP).

3. Output dari penelitian ini berfokus pada evaluasi kepuasan pengguna aplikasi OPAC Perpustakaan STMIK Amikom Yogyakarta dilihat dari lima perspektif yaitu isi (content), keakuratan (accuracy), bentuk (format), kemudahan penggunaan (ease of use) dan ketepatan waktu (timeliness) atau dengan metode yang dikenal dengan sebutan metode End-User Computing Satisfaction.

Ada beberapa acuan referensi penelitian yang digunakan sebagai pembanding dalam penelitian ini, di antaranya adalah penelitian OPAC yang dirangkum dalam jurnal "Use of Online Public Access Catalogue at Annamalai University Library"(S. Thanuskodi, 2012). Penelitian ini mengungkap gambaran umum dan kegunaan OPAC di perpustakaan Universitas Annamalai serta sejauh mana kepuasan pengguna layanan OPAC tersebut. Adapun hasil penelitian menyatakan bahwa OPAC Universitas Annamalai kurang optimal dalam memenuhi kebutuhan pengguna. [1]

Selain itu, terdapat penelitian yang berjudul "Kepuasan Pemustaka terhadap OPAC Perpustakaan UIN Sunan Kalijaga Yogyakarta" (Wahyani, dkk, 2012). Penelitian kualitatif ini bertujuan untuk mengevaluasi kepuasan pengguna aplikasi SIPRUS Perpustakaan UIN Sunan Kalijaga Yogyakarta. Adapun hasil penelitian menyatakan bahwa pemustaka merasa puas dengan kinerja OPAC. [2]

Terdapat pula penelitian berjudul "Kajian Pemanfaatan OPAC di Perpustakaan Universitas Swadaya Gunung Jati Cirebon" (Taufik Ridwan, 2011). Penelitian ini membahas pemanfaatan OPAC di Perpustakaan Universitas Swadaya Gunung Jati Cirebon. Namun penelitian ini berfokus pada sistem temu balik informasi pada OPAC dan hanya menilik OPAC dari sisi humaniora. Hasil penelitian menunjukkan OPAC dapat berjalan sesuai fungsinya dengan baik. [3]

Landasan teori yang digunakan dalam penelitian ini antara lain:

\subsection{Teori Kepuasan}

Nasutionmendefinisikankepuasan pengguna atau customer secara sederhana, yaitusuatu keadaan dimana kebutuhan, keinginan dan harapan pengguna dapat terpenuhimelalui produk yang digunakan. Kepuasan pengguna dapat dinyatakan dalam suaturasio sebagai berikut : $Z=X / Y$, dimana $\mathrm{Z}$ adalah kepuasan pengguna; $\mathrm{X}$ adalahkualitas yang dirasakan oleh pengguna; dan $\mathrm{Y}$ adalah kebutuhan,keinginan, danharapan pengguna. [4]

\subsection{Perpustakaan}

Menurut Shaleh, perpustakaan perguruan tinggi adalah unit penunjang bagi terselenggaranya tujuan perguruan tinggi, yaitu tri dharma perguruan tinggi yang terdiri dari pendidikan, penelitian dan pemberdayaan masyarakat. [5]

\subsection{Katalog Perpustakaan}

Menurut Hasugian, katalog perpustakaan adalah suatu daftar yang sistematis dari buku dan bahan-bahan lain dalam suatu perpustakaan dengan informasi deskriptif mengenaipengarang, judul, penerbit, tahun terbit, bentuk fisik, subjek, ciri khas bahan dantempatnya. Sedangkan katalog perpustakaan terdiri dari berbagaibentuk fisik antara lain, katalog berbentuk buku (book catalog), katalog berbentukkartu (card catalog),katalog berbentuk mikro (microform catalog), dan katalogkomputer terpasang (online computer catalog). [6]

\subsection{Online Public Access Catalog}


Menurut Horgan, OPAC adalah suatu sistem temu balik informasi, dengan satu sisi masukan (input) yang menggabungkan pembuatan file yang tercantum dan indeks. OPAC merupakan alatbantu untuk menelusuri informasi di perpustakaan yang menggunakan sistem komputer dengan jaringan LAN dan WAN. OPAC dinyatakan sebagai katalog yang interaktif. Disebut interaktif karenasistem tersebut menyediakan komunikasi antara pengguna dengan komputerdalamsuatu cara yang bersifat dialog. [7]

Menurut Hermanto, OPAC memiliki keuntungan, antara lain:

a. Penelusuran informasi dapat dilakukansecaracepat dan tepat.

b. Penelusuran dapat dilakukan di mana saja, tidak harus datang ke perpustakaandengan catatan sudah online ke internet.

c. Menghemat waktu dan tenaga sertapenggunamendapatkanpeluanglebih banyak dalammenelusuribahanpustaka. berikut:

Sedangkan menurut Hermanto, kekurangan OPAC pada umumnya adalah sebagai

a. Belum semua bahan pustaka masuk ke data komputer sehingga pengguna mengalami kesulitan dalam melakukan penelusuran.

b. Tergantung aliran listrik, bila listrik mati maka kegiatan penelusuran bahan pustaka akan terganggu.

c. Kurangnya ketersediaan komputer terminal OPAC untuk menelusuri informasi yang dimiliki perpustakaan. [8]

\subsection{End User Computing Satisfaction}

End User Computing Satisfaction (EUCS) adalah metode untuk mengukur tingkat kepuasan dari pengguna dari suatu sistem aplikasi dengan membandingkan antara harapan dengan kenyataan dari sebuah sistem informasi. Definisi EUCSdari sebuah sistem informasi adalah evaluasi secara keseluruhan dari para pengguna sistem informasi berdasarkan pengalaman mereka dalam menggunakan sistem informasi tersebut.

Model EUCS ini dikembangkan oleh Doll \& Torkzadeh pada tahun 1988 dimana keduanya menekankan pada kepuasan (satisfaction) pengguna akhir terhadap aspek teknologi. Penilaian kepuasan tersebut dilihat dari lima buah perspektif/dimensi yakni, isi (content), keakuratan (accuracy), bentuk (format), kemudahan penggunaan (ease of use) dan ketepatan waktu (timeliness). [9]

\subsubsection{Dimensi Isi (Content)}

Dimensi isi mengukur kepuasan pengguna ditinjau dari sisi isi (content) dari suatu sistem. Isi dari sistem biasanya berupa fungsi dan modul yang dapat digunakan oleh pengguna sistem dan juga informasi yang dihasilkan oleh sistem. Dimensi Content juga mengukur apakah sistem menghasilkan informasi yang sesuai dengan kebutuhan pengguna. Semakin lengkap modul dan informatif sistem, maka tingkat kepuasan dari pengguna akan semakin tinggi.

\subsubsection{Dimensi Akurat (Accuracy)}

Dimensi akurat mengukur kepuasan pengguna dari sisi keakuratan data ketika sistem menerima input kemudian mengolahnya menjadi informasi. Keakuratan sistem diukur dengan melihat seberapa sering sistem menghasilkan output yang salah ketika mengolah input dari pengguna, selain itu dapat dilihat pula seberapa sering terjadi error atau kesalahan dalam proses pengolahan data.

\subsubsection{Dimensi Bentuk (Format)}

Dimensi bentuk mengukur kepuasan pengguna dari sisi tampilan dan estetika dari antarmuka sistem, bentukdari laporan atau informasi yang dihasilkan oleh sistem apakah 
antarmuka dari sistem itu menarik dan apakah tampilan dari sistem memudahkan pengguna ketika menggunakan sistem sehingga secara tidak langsung dapat berpengaruh terhadap tingkat efektifitas dari pengguna.

\subsubsection{Dimensi Kemudahan Penggunaan}

Dimensi kemudahan penggunaan (Ease of Use) mengukur kepuasan pengguna dari sisi kemudahan pengguna atau user friendly dalam menggunakan sistem seperti proses memasukkan data, mengolah data dan mencari informasi yang dibutuhkan.

\subsubsection{Dimensi Ketepatan Waktu}

Dimensi ketepatan waktu (Timeliness)mengukur kepuasan pengguna dari sisi ketepatan waktu sistem dalam menyajikan data dan informasi yang dibutuhkan oleh pengguna. Sistem yang tepat waktu dapat dikategorikan sebagai sistem real-time, berarti setiap permintaan atau input yang dilakukan oleh pengguna akan langsung diproses dan output akan ditampilkan secara cepat tanpa harus menunggu lama.

\section{METODE PENELITIAN}

Metodeyang digunakan dalam penelitian ini adalah metode survey deskriptif. Metode ini mengambil sampel dari suatu populasi dan menggunakan kuesioner sebagai alat pengumpulan data. Dalam penelitian ini, peneliti mengambil sampel sejumlah 250 responden yang dianggap mewakili populasi pengguna aktif Perpustakaan STMIK AMIKOM Yogyakarta $( \pm 2.500$ orang $)$ bawah:

Adapun metode analisa data menggunakan rumus Mean yang ditunjukkan persamaan di

$$
(X)=\frac{\sum x}{N}
$$

Ket:

$\mathrm{X}=$ Rata-rata hitung

$\Sigma \mathrm{x}=$ Jumlah semua nilai kuesioner

$\mathrm{N}=$ Jumlah responden

Indeks Kepuasan Pengguna (IKP) merupakan analisis kuantitatif berupapersentasepengguna yang senang dalam suatu survei kepuasan pengguna. IKPdiperlukan untuk mengetahui tingkat kepuasan pengguna secara menyeluruh denganmemperhatikantingkat kepentingan dari indikator-indikator produk atau jasa tersebut.

Tabel 1. Indeks Kepuasan Pengguna

\begin{tabular}{|c|c|c|c|}
\hline \multirow[t]{2}{*}{ Indikator } & $\begin{array}{l}\text { Kepentingan } \\
\text { (I) }\end{array}$ & $\begin{array}{c}\text { Kepuasan } \\
(\mathrm{P})\end{array}$ & Skor (S) \\
\hline & $\begin{array}{l}\text { Skala: } \\
(1-5)\end{array}$ & $\begin{array}{l}\text { Skala: } \\
(1-5)\end{array}$ & $\begin{array}{c}\text { (S) }= \\
\text { (I) X (P) }\end{array}$ \\
\hline$\ldots$ & $\ldots$ & $\ldots$ & $\ldots$ \\
\hline$\ldots$ & $\ldots$ & $\ldots$ & $\ldots$ \\
\hline Skor & $(\mathrm{I})=(\mathrm{Y})$ & & $(\mathrm{S})=(\mathrm{T})$ \\
\hline
\end{tabular}

Nilai rata-rata pada kolom kepentingan (I) dijumlahkan sehingga diperolehYdan juga hasil kali I dengan $\mathrm{P}$ pada kolom skor (S) dijumlahkan dan diperoleh T.IKP diperoleh dari perhitungan IKP $=(\mathrm{T} / 5 \mathrm{Y}) \times 100 \%$. Nilai 5 (pada $5 \mathrm{Y}$ ) adalah nilaimaksimum yang digunakan pada skala pengukuran.Nilai maksimum IKP adalah 100\%. NilailKP 50\% atau lebih rendahmenandakan kinerja pelayanan yang kurang baik di mata pengguna. Nilai IKP 80\%atau 
lebih tinggi mengindikasikan pengguna merasa puas terhadap kinerja pelayanan. (Suparman, 2007)

Importance Performance Analysis (IPA) yaitu suatu analisis yang mengkaitkan antara tingkat kepentingan (importance) suatu indikator yang dimiliki obyek tertentu dengan kenyataan (performance) yang dirasakan olehpengguna. Menurut Suparman, diagram IPA terdiri dari empat kuadran yaitu sebagai berikut [10]:

1. Kuadran I, wilayah yang memuat indikator-indikator dengan tingkat kepentingan yang relatif tinggi tetapi kenyataannya belum sesuai dengan yang pengguna harapkan. Indikator-indikator yang masuk kuadran ini harus segera ditingkatkan kinerjanya.

2. Kuadran II, wilayah yang memuat indikator-indikator dengan tingkat kepentingan yang relatif tinggi dengan tingkat kepuasan yang relatif tinggi pula. Indikator-indikator yang masuk kuadran ini harus tetap dipertahankan kinerjanya karena semua indikator ini menjadikan produk atau jasa tersebut unggul di mata pengguna.

3. Kuadran III, wilayah yang memuat indikator-indikator dengan tingkat kepentingan yang relatif rendah dan kenyataannya kinerjanya tidak terlalu istimewa dengan tingkat kepuasan yang relatif rendah. Indikator-indikator yang masuk kuadran ini memberikan pengaruh sangat kecil terhadap manfaat yang dirasakan pengguna.

4. Kuadran IV, wilayah yang memuat indikator-indikator dengan tingkat kepentingan yang relatif rendah dan dirasakan oleh pengguna terlalu berlebihan dengan tingkat kepuasan yang relatif tinggi. Biaya yang digunakan untuk menunjang indikator yang masuk kuadran ini dapat dikurangi agar perusahaan dapat menghemat pengeluaran.

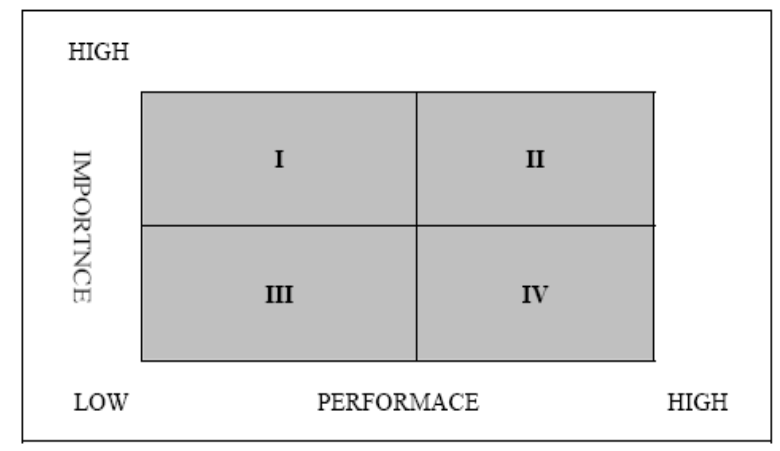

Gambar 1. Diagram IPA

\section{HASIL PENELITIAN}

\subsection{Gambaran Perpustakaan STMIK AMIKOM Yogyakarta}

Perpustakaan STMIK AMIKOM Yogyakarta berdiri bersamaan dengan berdirinya STMIK AMIKOM bertempat di kampus I, Jl. Wolter Monginsidi No. Yogyakarta. Kemudian STMIK AMIKOM mendirikan kampus II di Jl. Kaliurang Km 5,6 No. 75, maka Perpustakaan STMIK Amikom berlokasi di dua tempat. Pada tahun akademik 1998/1999, STMIK Amikom resmi menempati kampus baru di Ring Road Utara, Condong Catur. Saat ini Perpustakaan STMIK Amikom Yogyakarta terletak di gedung unit V lantai 1.

Perpustakaan STMIK AMIKOM Yogyakarta merupakan perpustakaan dengan koleksicetak dan audiovisual. Koleksi cetak berupa buku, majalah, surat kabar, kliping, laporan tugas akhir atau skripsi, sedangkan koleksi audiovisual berupa CompactDisk (CD), disket, kaset dan DVD. Koleksi buku yang dimiliki secara umum dibagi menjadi dua golongan, yang pertama adalah buku-buku yang dipergunakan untuk mendukung perkuliahan sehari-hari berupa diktat kuliah dan buku acuan untuk mahasiswa. Sementara sebagian berupa buku Referensi yang merupakan buku berbahasa asing atau Inggris untuk tujuan pengembangan ilmu pengetahuan dan teknologi. 


\subsection{Gambaran OPAC Perpustakaan STMIK AMIKOM Yogyakarta}

Perpustakaan STMIK AMIKOM Yogyakarta dilengkapi OPAC di mana terdapat Digital Library untuk mencari buku dan CD di perpustakaan. Aplikasi digital library ini dapat diakses di anjungan perpustakaan STMIK AMIKOM Yogyakarta yang tersedia maupun di internet melalui diglib.amikom.ac.id. Layanan yang disediakan web Perpustakaan STMIK AMIKOM Yogyakarta antara lain informasi yang berkaitan tentang layanan perpustakaan, katalog sebagai sarana penelusuran informasi dan statistik koleksi. Web ini juga menampilkan beberapa buku baru yang tersedia di Perpustakaan STMIK AMIKOM Yogykarta. Selain itu, digital library ini juga menghubungkan dengan beberapa link seperti ProQuest, EbscoHost, jurnal Garuda dan lain-lain.

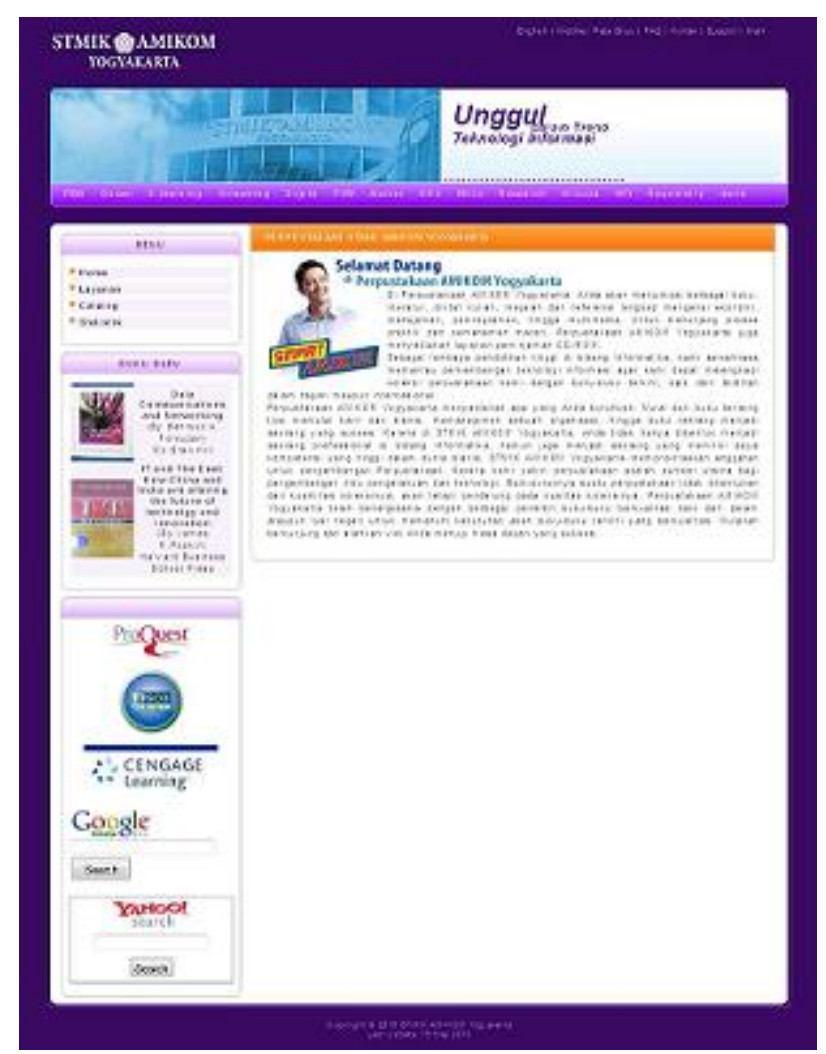

Gambar 2. Halaman Depan OPAC Perpustakaan STMIK AMIKOM Yogyakarta

\subsection{Deskripsi Responden}

Berdasarkan data statistik Perpustakaan (2013), pengunjung aktif Perpustakaan STMIK AMIKOM Yogyakarta berjumlah kurang lebih 2.500 orang. Adapun jumlah kuesioner yang disebar berjumlah 250 eksemplar untuk 250 responden. 
Tabel 2. Responden Berdasarkan Jenis Kelamin

\begin{tabular}{|l|l|l|}
\hline Jenis Kelamin & Jumlah & Persentase \\
\hline Pria & 102 & $40,80 \%$ \\
\hline Wanita & 148 & $59,20 \%$ \\
\hline Total & 250 & $100 \%$ \\
\hline
\end{tabular}

Tabel 3. Responden Berdasarkan Jurusan

\begin{tabular}{|l|l|l|}
\hline Jurusan & Jumlah & Persentase \\
\hline D3 Manajemen Informatika & 41 & $16,40 \%$ \\
\hline S1 Sistem Informasi & 86 & $34,40 \%$ \\
\hline D3 Teknik Informatika & 33 & $13,20 \%$ \\
\hline S1 Teknik Informatika & 74 & $29,60 \%$ \\
\hline S2 Magister Teknik Informatika & 16 & $6,40 \%$ \\
\hline Total & 250 & $100 \%$ \\
\hline
\end{tabular}

Tabel 4. Responden Berdasarkan Tahun Angkatan

\begin{tabular}{|l|l|l|}
\hline Tahun Angkatan & Jumlah & Persentase \\
\hline 2009 & 63 & $25,20 \%$ \\
\hline 2010 & 89 & $35,60 \%$ \\
\hline 2011 & 58 & $23,20 \%$ \\
\hline 2012 & 40 & $16 \%$ \\
\hline Total & 250 & $100 \%$ \\
\hline
\end{tabular}

Tabel 5. Responden Berdasarkan Intensitas Kunjungan ke Perpustakaan

\begin{tabular}{|l|l|l|}
\hline Intensitas & Jumlah & Persentase \\
\hline $1-2$ kali & 145 & $58 \%$ \\
\hline $3-4$ kali & 78 & $31,20 \%$ \\
\hline $5-6$ kali & 21 & $8,4 \%$ \\
\hline$>6$ kali & 6 & $2,4 \%$ \\
\hline Total & 250 & $100 \%$ \\
\hline
\end{tabular}

Tabel 6. Responden Berdasarkan Intensitas Penggunaan OPAC

\begin{tabular}{|l|l|l|}
\hline Intensitas & Jumlah & Persentase \\
\hline Sering Sekali & 56 & $22,4 \%$ \\
\hline Sering & 125 & $50 \%$ \\
\hline Biasa & 43 & $17,2 \%$ \\
\hline Jarang & 24 & $9,6 \%$ \\
\hline Jarang Sekali & 2 & $0,8 \%$ \\
\hline Total & 250 & $100 \%$ \\
\hline
\end{tabular}

\subsection{Importance Performance Analysis (IPA)}

Nilai rata-rata total dan nilai rata-rata setiap dimensi serta indikator tingkat kepuasan pengguna terhadap OPAC Perpustakaan STMIK Amikom Yogyakarta diperlihatkan pada tabel 7. Pada tabel tersebut dapat dilihat bahwa nilai rata-rata total untuk tingkat kepentingan (importance) dan yang dirasakan atau kinerja (performance), masing-masing adalah 4,13dan 3,90. Perpotongan sumbu dari kedua nilai rata-rata total ini akan menjadi pemisahdari keempat kuadran pada diagram hasil IPA. 
Citec Journal, Vol. 1, No. 1, November 2013 - Januari 2014

Tabel 7. Nilai Persen Kepuasan

\begin{tabular}{|c|c|c|c|}
\hline Indikator & $\begin{array}{l}\text { Harapan } \\
\text { (I) }\end{array}$ & $\begin{array}{l}\text { Kenyataan } \\
\text { (P) }\end{array}$ & $\begin{array}{c}\text { Persen Kepuasan } \\
\text { (P / I) X } 100 \%\end{array}$ \\
\hline \multicolumn{4}{|l|}{ Isi (Content) } \\
\hline $\mathrm{X} 1$ & 4,15 & 3,97 & 95,66 \\
\hline $\mathrm{X} 2$ & 4,41 & 3,88 & 87,98 \\
\hline $\mathrm{X} 3$ & 4,13 & 3,85 & 93,22 \\
\hline $\mathrm{X} 4$ & 3,98 & 3,93 & 98,74 \\
\hline $\mathrm{X} 5$ & 4,07 & 3,95 & 97,05 \\
\hline Rata-Rata Isi & 4,15 & 3,92 & 94,53 \\
\hline \multicolumn{4}{|l|}{ Akurat (Accuracy) } \\
\hline X6 & 4,02 & 3,92 & 97,51 \\
\hline $\mathrm{X} 7$ & 4,27 & 3,93 & 92,04 \\
\hline Rata-Rata Akurat & 4,15 & 3,93 & 94,78 \\
\hline \multicolumn{4}{|l|}{ Bentuk (Format) } \\
\hline $\mathrm{X} 8$ & 4,29 & 3,91 & 91,14 \\
\hline $\mathrm{X9}$ & 4,17 & 3,73 & 89,45 \\
\hline $\mathrm{X} 10$ & 4,17 & 4,01 & 96,16 \\
\hline $\mathrm{X} 11$ & 3,90 & 3,70 & 94,87 \\
\hline Rata-Rata Bentuk & 4,13 & 3,84 & 92,91 \\
\hline \multicolumn{4}{|c|}{ Kemudahan Penggunaan (Ease Of Use) } \\
\hline $\mathrm{X} 12$ & 4,08 & 4,01 & 98,28 \\
\hline $\mathrm{X} 13$ & 4,02 & 3,95 & 98,26 \\
\hline $\mathrm{X} 14$ & 4,19 & 3,84 & 91,65 \\
\hline $\mathrm{X} 15$ & 4,14 & 4,02 & 97,10 \\
\hline Rata-Rata Mudah & 4,11 & 3,96 & 96,32 \\
\hline \multicolumn{4}{|c|}{ Ketepatan Waktu (Timeliness) } \\
\hline $\mathrm{X} 16$ & 4,12 & 4,00 & 97,09 \\
\hline $\mathrm{X} 17$ & 4,11 & 3,70 & 90,02 \\
\hline Rata-Rata Tepat & 4,12 & $\mathbf{3 , 8 5}$ & 93,56 \\
\hline Rata-Rata Total & 4,13 & 3,90 & 94,42 \\
\hline
\end{tabular}

Gambar 3. di bawah ini memperlihatkan diagram hasil IPA yang merupakan posisi indikator di masing-masing kuadran. Posisi indikator tersebut merupakan posisi relatif sehingga dapat berubah apabila ada satu atau lebih indikator yang nilai rata-ratanya berubah. Penentuan posisi ini berdasarkan nilai rata-rata indikator, sedangkan untuk sumbu importance dan performance merupakan rata-rata total dari seluruh nilai rata-rata indikator. Dengan demikian posisi indikator maupun posisi sumbu saling mempengaruhi satu sama lain. 


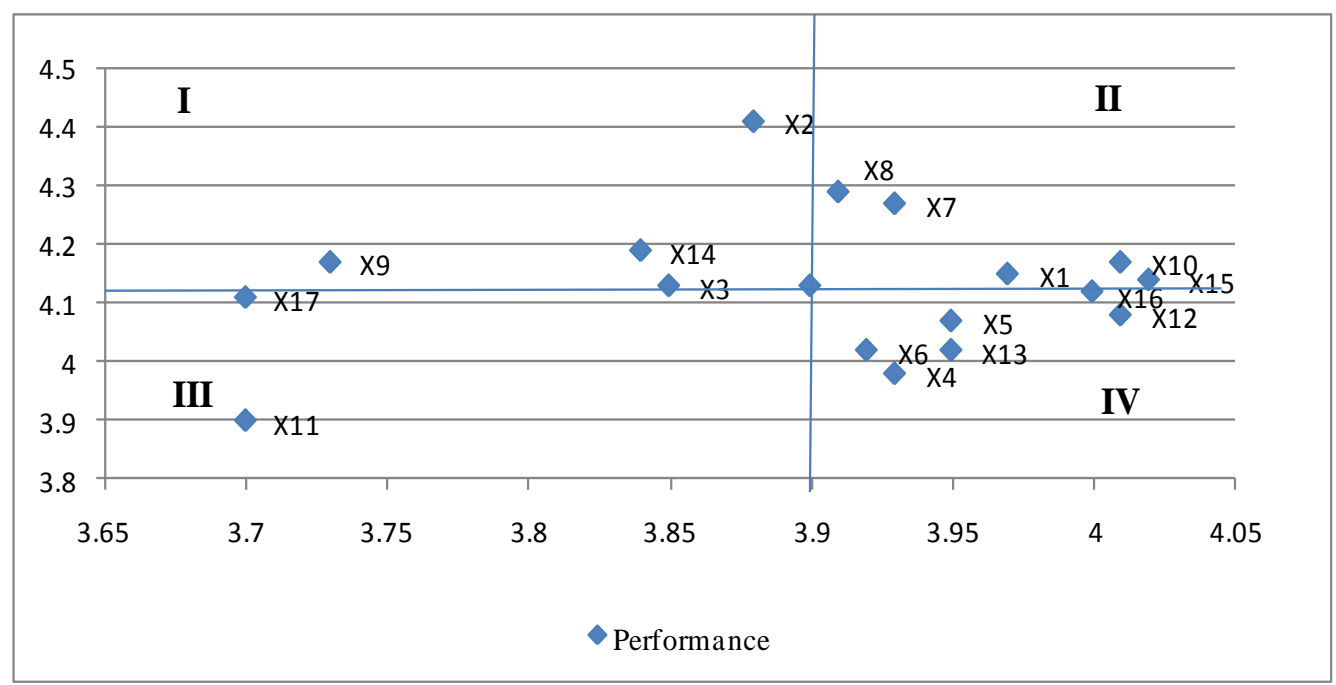

Gambar 3. Hasil Diagram IPA

3.5. Indeks Kepuasan Pengguna (IKP)

Tabel 8. Hasil Perhitungan IKP

\begin{tabular}{|c|c|c|c|}
\hline \multirow[b]{2}{*}{ Indikator } & Kepentingan (I) & Kepuasan (P) & Skor (S) \\
\hline & $\begin{array}{c}\text { Skala: } \\
\text { 5-Jan } \\
\end{array}$ & $\begin{array}{l}\text { Skala: } \\
\text { 5-Jan }\end{array}$ & $(S)=(I) X(P)$ \\
\hline $\mathrm{X1}$ & 4,15 & 3,97 & 16,48 \\
\hline $\mathrm{X} 2$ & 4,41 & 3,88 & 17,11 \\
\hline $\mathbf{X 3}$ & 4,13 & 3,85 & 15,90 \\
\hline $\mathrm{X4}$ & 3,98 & 3,93 & 15,64 \\
\hline $\mathrm{X5}$ & 4,07 & 3,95 & 16,08 \\
\hline$\overline{X 6}$ & 4,02 & 3,92 & 15,76 \\
\hline $\mathrm{X} 7$ & 4,27 & 3,93 & 16,78 \\
\hline $\mathrm{X8}$ & 4,29 & 3,91 & 16,77 \\
\hline X9 & 4,17 & 3,73 & 15,55 \\
\hline $\mathbf{X 1 0}$ & 4,17 & 4,01 & 16,72 \\
\hline X11 & 3,90 & 3,70 & 14,43 \\
\hline X12 & 4,08 & 4,01 & 16,36 \\
\hline $\mathrm{X13}$ & 4,02 & 3,95 & 15,88 \\
\hline X14 & 4,19 & 3,84 & 16,09 \\
\hline X15 & 4,14 & 4,02 & 16,64 \\
\hline $\mathrm{X} 16$ & 4,12 & 4,00 & 16,48 \\
\hline $\mathrm{X17}$ & 4,11 & 3,70 & 15,21 \\
\hline Skor Total & 70,22 & & 273,88 \\
\hline
\end{tabular}

Berdasarkan perhitungan pada tabel 8, diperoleh hasil IKP sebesar 78,01\%. Dengan nilai IKP tersebut, dapat diartikan bahwa pengguna OPAC Perpustakaan STMIK AMIKOM Yogyakarta merasa cukup puas atas kinerja OPAC. Oleh karena itu, pihak pengelola OPAC Perpustakaan STMIK AMIKOM Yogyakarta harus memperbaiki dan meningkatkan kinerja pelayanan. 


\section{KESIMPULAN}

Berdasarkan hasil penelitian yang telah dilakukan, dapat ditarik beberapa kesimpulan sebagai berikut :

1. Perpustakaan STMIK AMIKOM Yogyakarta dilengkapi OPAC di mana terdapat Digital Library untuk mencari buku, CD, TA/skripsi dan berbagai koleksi di perpustakaan. Aplikasi digital library ini dapat diakses di anjungan perpustakaan STMIK AMIKOM Yogyakarta yang tersedia maupun di internet melalui diglib.amikom.ac.id. Selain itu, digital library ini juga menghubungkan dengan beberapa link jurnal seperti ProQuest, EbscoHost, jurnal Garuda dan lain-lain serta search engine seperti Yahoo dan Google.

2. Cara mengevaluasi kepuasan pengguna OPAC Perpustakaan STMIK AMIKOM Yogyakarta adalah dengan menggunakan diagram Importance Performance Analysis dipadukan dengan Indeks Kepuasan Pengguna didasarkan pada indikator-indikator dari lima dimensi End User Computing Satisfaction.

3. Tingkat kepuasan pengguna OPAC dapat dilihat dari hasil IKP sebesar 78,01\%. Dengan nilai IKP tersebut, dapat diartikan bahwa pengguna OPAC Perpustakaan STMIK AMIKOM Yogyakarta merasa cukup puas atas kinerja OPAC. Namun pihak pengelola perpustakaan harus memperbaiki dan meningkatkan kinerja pelayanannya yang terdapat pada kuadran I diagram hasil IPA. Dengan usaha-usahatersebut, diharapkan terjadi peningkatan nilai IKP secarakeseluruhan.

\section{SARAN}

Berikut adalah saran-saran yang dapat dijadikan acuan untuk meningkatkan kinerja OPAC STMIK Amikom Yogyakarta yang dapat berdampak pada kepuasan pengguna OPAC selanjutnya :

1. Kontrol terhadap informasi yang dihasilkan OPAC lebih diperhatikan, seperti pada output informasi letak koleksi, jumlah ketersediaan buku, dan lain-lain.

2. Update informasi pada OPAC baiknya dilakukan secara periodik, agar informasi pada OPAC selalu up to date sehingga memudahkan pengguna untuk mencari informasi koleksi perpustakaan yang dibutuhkan.

3. Pemeliharaan anjungan dan fasilitas komputer yang tersedia di Perpustakaan STMIK AMIKOM Yogyakarta perlu diperhatikan, agar terawat baik dan selalu dapat dimanfaatkan sesuai fungsinya.

\section{DAFTAR PUSTAKA}

[1] Thanuskodi, S., 2012, Use of Online PublicAccess Catalogue at Annamalai University Library, International Journal of Information Science, Vol. 2, No. 6, hal 70-74.

[2] Wahyani, Yuliana, C. P., Septiani, R., 2012, Kepuasan Pemustaka Terhadap OPAC Perpustakaan UIN Sunan Kalijaga Yogyakarta, UIN Sunan Kalijaga, Yogyakarta.

[3] Ridwan, Taufik, 2011, Kajian Pemanfaatan OPAC di Perpustakaan Universitas Swadaya Gunung Jati Cirebon, Magister Ilmu Perpustakaan, Universitas Indonesia,

[4] Nasution, M. N., 2004, Manajemen Mutu Terpadu (Total Quality Management), Ghalia Indonesia, Jakarta.

[5] Saleh, A. R., 2004, Standar Kompetensi dan Masa Depan Pustakawan Indonesia dalam Dinamika Perpustakaan IPB Menuju Perpustakaan Riset, IPB Press, Bogor.

[6] Hasugian, J., 2003, Katalog Perpustakaan Dari Katalog Manual Sampai Katalog Online $(O P A C)$, UPT Perpustakaan USU, Medan. 
[7] Horgan, G. P., 1994, Staff Use of Online Public Access Catalogues (OPAC) in an University Library, University of Wales.

[8] Hermanto, B., 2010, Manfaat Katalog Online, http://bambanguns.com/2010//05/manfaatkatalog-online.html?m=1, diakses tanggal 15 Agustus 2013.

[9] Doll, W. J., Torkzadeh, G., 1988, The Measurement of End User Computing Satisfaction, MIS Quarterly, Vol 12, No 2, hal 259-274.

[10] Suparman, 2007, Kajian Kepuasan PenggunaTerhadap Kualitas Layanan Perpustakaan Institut Pertanian Bogor,Magister Manajemen, Bogor. 